\title{
Load-locked dc high voltage GaAs photogun with an inverted-geometry ceramic insulator
}

\author{
P. A. Adderley, J. Clark, J. Grames, J. Hansknecht, K. Surles-Law, D. Machie, M. Poelker,* \\ M. L. Stutzman, and R. Suleiman \\ Thomas Jefferson National Accelerator Facility, Newport News, Virginia 23606, USA
}

(Received 24 November 2009; published 26 January 2010)

\begin{abstract}
A new dc high voltage spin-polarized photoelectron gun has been constructed that employs a compact inverted-geometry ceramic insulator. Photogun performance at $100 \mathrm{kV}$ bias voltage is summarized.

DOI: 10.1103/PhysRevSTAB.13.010101

PACS numbers: 29.27.Hj, 29.25.Bx, 41.75.Fr
\end{abstract}

\section{INTRODUCTION}

All of the nuclear physics experiments conducted at the Continuous Electron Beam Accelerator Facility (CEBAF) at the Thomas Jefferson National Accelerator Facility (Jefferson Lab) receive electron beams from a dc high voltage spin-polarized GaAs photoemission gun. Since 1995, the year the first polarized electron source was installed at CEBAF [1], there have been four different photogun designs with each new gun an improvement over its predecessor. The most recent design employs a compact, tapered ceramic insulator that extends into the vacuum chamber. This gun geometry is commonly referred to as an "inverted" gun design, a reference to the first such implementation by Breidenbach et al., at SLAC [2]. The main reason for pursuing the inverted ceramic design at Jefferson Lab was to help overcome field emission problems of the previous gun design that used a conventional large-bore cylindrical ceramic insulator common to most dc high voltage spin-polarized GaAs photoguns worldwide [3-7]. The inverted insulator design helped to eliminate field emission because it provided a means to increase the distance between biased and grounded parts of the photogun. This helped reduce the field gradient at some locations not related to beam delivery. Perhaps more importantly, the design significantly reduced the amount of metal biased at high voltage, so there is less metal to generate field emission. Another appealing feature of the design is that the insulator is a common element of medical x-ray sources, and therefore relatively inexpensive compared to cylindrical insulators purchased solely for accelerator electron gun applications. This paper describes the CEBAF invertedgun design, construction, and performance.

\section{OLD AND NEW GUN DISCUSSION}

Reliable dc high voltage GaAs photoguns with a long operating lifetime have demanding requirements: exceptionally good vacuum, clean photocathode surfaces, stable rf-pulsed drive lasers, properly designed electrodes for efficient beam transport, and a complete absence of field emission. As mentioned above, the inverted-gun design

*Corresponding author: poelker@jlab.org was pursued at Jefferson Lab primarily to help eliminate field emission. Figure 1 shows a side-by-side comparison of the high voltage chambers of the two most recent CEBAF photogun designs: the previous design with a large-bore cylindrical ceramic insulator [Fig. 1(a)] and the new design with an inverted insulator [Fig. 1(b)]. Both guns rely on a "side-ceramic" approach, with the ceramic insulator oriented perpendicular to the electron beam path, and with photocathode samples inserted into the hollow cathode electrode from behind. Both designs have similar cathode/anode electrode shapes at the vicinity of photocathode that provide similar electrostatic focusing appropriate for CEBAF beam conditions (100 $\mu \mathrm{A}$ average current, $499 \mathrm{MHz}$ pulse repetition rate, and $0.13 \mathrm{pC}$ bunch charge).

The gun with the conventional cylindrical large-bore ceramic insulator was CEBAF's first load-locked gun. It was commissioned during 2006 at a test facility and installed at CEBAF in 2007. During commissioning, the gun performed very well, operating at current between $250 \mu \mathrm{A}$ and $1 \mathrm{~mA}$ with charge lifetime $\sim 200 \mathrm{C}$ from strained superlattice GaAs/GaAsP [8], where "charge lifetime" is a metric describing the amount of charge that can be extracted from the photogun before photocathode quantum efficiency $(\mathrm{QE})$ falls to $1 / e$ of its initial value. Unfortunately, the gun exhibited only $30 \mathrm{C}$ charge lifetime at CEBAF while operating at just $60 \mu \mathrm{A}$ average current throughout two years of operation. Although this was enough to satisfy the requirements of the nuclear physics program, it was disappointing compared to commissioning results. Troubleshooting revealed a small amount of field emission measured at the electrically isolated anode plate ( $\sim 200 \mathrm{pA}$ ) correlated with a very small vacuum increase detectable using an ion pump power supply with extremely sensitive current monitoring capability [9]. This low level of field emission was not catastrophic in the sense that the photogun could be biased at high voltage and still provide high-quality polarized electron beam. In fact, without the electrically isolated anode and sensitive ion pump current monitoring tool, the field emission would have been difficult to detect (albeit, QE was degrading faster than expected). Constant low-level field emission most likely explains the poor charge lifetime because it degrades vac- 


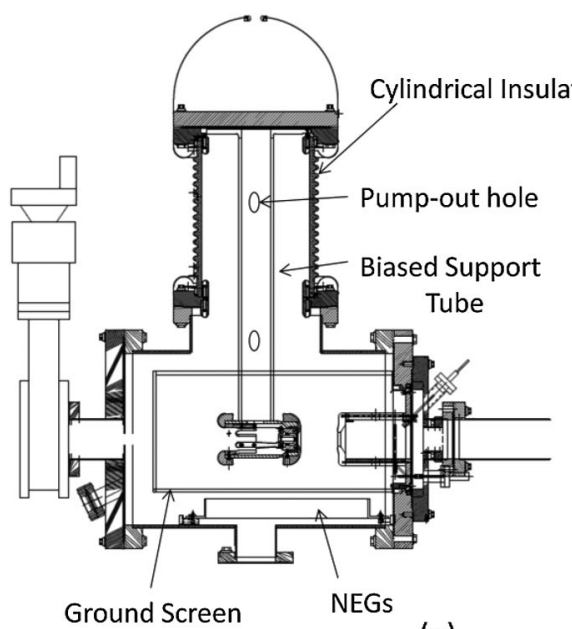

(a)

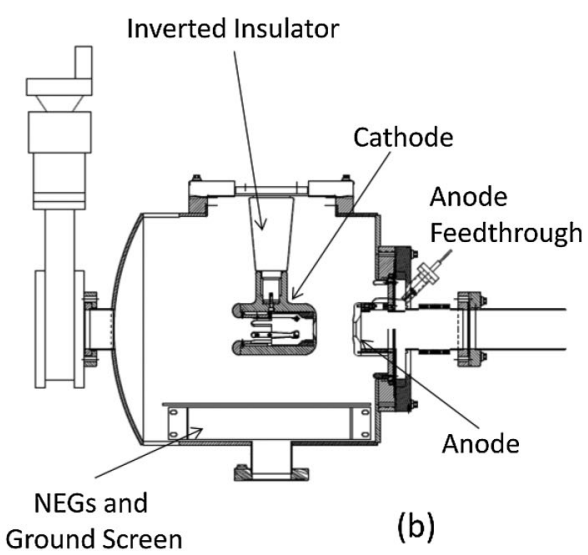

Ground Screen

FIG. 1. Diagrams of the two recent gun designs: (a) conventional large-bore cylindrical insulator and (b) inverted gun with compact tapered insulator that extends into the gun vacuum vessel. Both drawings have the same scale with top flanges $10^{\prime \prime}$ diameter. The cathode/anode gap is $\sim 6 \mathrm{~cm}$ for both designs.

uum within the gun, reducing gun lifetime via electron stimulated desorption of gas and subsequent enhanced loss of photocathode QE from ion backbombardment, at the location of the drive laser beam and along a line toward the electrostatic center of the photocathode. Field emission also serves to liberate chemically reactive gas, which degrades QE across the entire photocathode surface. Furthermore, field emission generates $\mathrm{x}$ rays which can in turn generate unwanted photoemission from the cathode electrode and portions of the photocathode that do not support efficient beam transport, amplifying the ill effects of ion backbombardment and chemical poisoning.

It is not clear why the gun functioned well and without field emission during commissioning but not at CEBAF. Upon disassembly and inspection, a small blemish on the high-gradient region of the cathode electrode was visible to the unaided eye. This blemish was not present at the time of construction and required repolishing with diamond paste to remove. Perhaps the blemish was indication of a subsurface defect in the material that eventually worked its way to the surface and generated field emission. It is also possible field emission was prompted as a result of venting, moving, and rebaking the gun. For example, some speculate that "dust" can contribute to field emission [10] and it is certainly possible that dust could have been liberated from some region of the gun and deposited on the electrode or support tube during the move to CEBAF.

Although the exact origin of this low-level field emission was never definitively identified, a decision was made to redesign the photogun to correct perceived flaws at two locations that might contribute to field emission: the electrode support tube near the grounded end of the ceramic insulator (3.9 MV/m with $4.4 \mathrm{~cm}$ gap), and the cathode electrode near the ground cage that "shields" the nonevaporable getter (NEG) pump modules $(5.3 \mathrm{MV} / \mathrm{m}$ with
$3.6 \mathrm{~cm}$ gap). These locations experience field gradient comparable to the transport-related gradient within the cathode/anode gap: $4.5 \mathrm{MV} / \mathrm{m}$ with $6.3 \mathrm{~cm}$ gap. Many photoguns operate without field emission at this gradient and higher, but care must be taken to ensure the electrodes are manufactured properly and from high-quality material free of defects. Traditionally, photogun electrodes have been manufactured from vacuum-arc remelt stainless steel, polished by hand to submicron finish with diamond paste [11] and, indeed, this was the case for the portion of the electrode facing the anode. In hindsight, however, not enough attention was paid to the other high-gradient regions mentioned above. The long support tube passing through the center of the insulator was not vacuum-arc remelt stainless steel, nor was it hand polished with diamond paste to obtain the best possible surface finish, particularly near the holes that allow pumping of the cylinder's interior. The second suspect region-the portion of the cathode electrode that faces a ground cage designed to shield the NEG pumps with their exposed ceramic washer standoffs-was simply located too close to ground potential.

The field emission problems of the first gun might have been solved by spending more time polishing the support tube and/or by using a cylindrical insulator with a larger bore (to increase the distance between the biased support tube and the insulator ground flange) but large ceramic insulators are expensive and take months to build [12-14]. Instead, an alternative approach was pursued using a tapered ceramic insulator common to medical $\mathrm{x}$-ray sources [15]. The inverted design eliminates the support tube passing close to the ground and significantly reduces the amount of metal biased at high voltage. Less metal means there is less material to polish, and less material to generate field emission. In addition, a larger diameter vacuum vessel 
was employed to move the NEGs and ground-shield cage further from the electrode.

Although the CEBAF inverted-gun high voltage insulator is not explicitly an "off-the-shelf" commercial item, it is very similar to insulators used on common medical x-ray sources, and therefore relatively simple to manufacture. The insulator is approximately $13 \mathrm{~cm}$ long with an outer diameter tapering from 7 to $5 \mathrm{~cm}$. The interior dimensions of the insulator (i.e., on the atmosphere side) accommodate an industry-standard high voltage connector [16]. The vendor delivered the insulator with the "grounded" end brazed to a kovar ring and welded to a 304L stainless steel disk, which was then welded to a $10^{\prime \prime}$ diameter Conflat ${ }^{\circledR}$ (CF) flange at Jefferson Lab. The cathode electrode bolts to a $2.5 \mathrm{~cm}$ diameter molybdenum plug brazed to the high voltage end of the insulator, and delivered with a tapped hole and slot for a "key" to capture and orient the electrode relative to the $10^{\prime \prime} \mathrm{CF}$ flange. A thin layer of silicone grease [17], with embedded alumina particulate, must be applied to the high voltage cable before it is inserted into the insulator to eliminate arcing to the ground. The tapered design of the insulator and connector ensure that air bubbles are squeezed out, and not trapped in the joint. Because there is no exposed high voltage, corona shields and a tank for dry nitrogen gas or $\mathrm{SF}_{6}$ are not required. Although the gun at CEBAF operates at $100 \mathrm{kV}$, the insulator was successfully tested to $225 \mathrm{kV}$-the maximum of our high voltage supply.

The cathode electrode was manufactured from two pieces of vacuum-arc remelt 316LN stainless steel [18] to minimize the number of joints and thereby ensure as smooth a surface as possible. No welding was performed. The two pieces have the same outer diameter and exhibit a smooth surface across the joint, thereby eliminating the abrupt discontinuities of the electrode structure of the previous gun design. The back face of the electrode attaches to the main cathode electrode body with set screws and serves to capture a spring assembly used to hold photocathode "pucks" inside the hollow electrode structure. The surface area of the cylindrical portion of the electrode parallel to the beam direction is roughly the same as the old gun design, but the surface area of the off-axis structure is considerably reduced: $\sim 70 \mathrm{~cm}^{2}$ compared to $\sim 700 \mathrm{~cm}^{2}$ of the previous gun design with long support tube.

An electrostatic field gradient map of the new gun design is shown in Fig. 2 [19]. The maximum field gradient within the cathode/anode gap is the same as the previous gun design, $4.5 \mathrm{MV} / \mathrm{m}$. By choosing a larger vacuum vessel, it was possible to reduce the field gradient between the cathode electrode and the NEG pumps and ground screen considerably: now only $\sim 3 \mathrm{MV} / \mathrm{m}$. There is one unintended high field gradient region on the new gun-at the joint where the cathode electrode meets the inverted ceramic insulator, with field gradient $\sim 7 \mathrm{MV} / \mathrm{m}$. This value is larger than originally intended-we had hoped to keep the field gradient below $5 \mathrm{MV} / \mathrm{m}$ everywhere in the gun. But the distance between this region and the nearest grounded surface is large $(\sim 20 \mathrm{~cm})$, and data from a field emission test stand indicate large gaps support higher gradient for a fixed potential difference [20].

Both of these asymmetric designs introduce a deflection of the beam as the electrons traverse the cathode/anode gap, but the "kick" is less severe for the inverted gun because there is less off-axis metal biased at high voltage. Beam transport features will be described in a future publication.

\section{MANUFACTURING THE NEW GUN}

Both pieces of the cathode electrode were manufactured using a 5-axis milling machine with computer numeric control. Machining was specified to provide a finish with 16 to 32 micro-inch rms surface roughness, obtained using
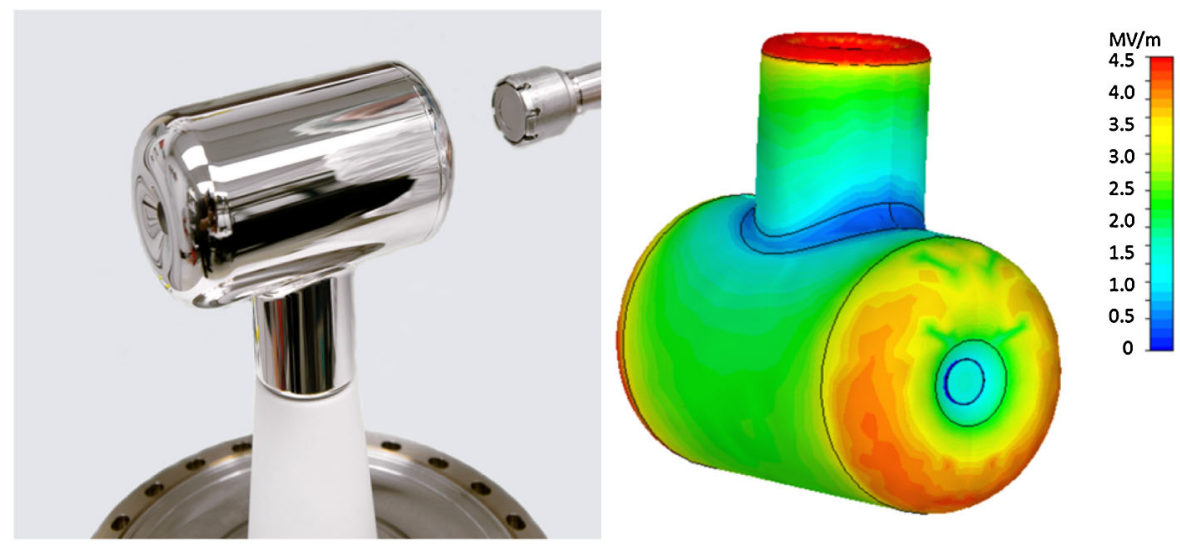

FIG. 2. (Color) Electrostatic field gradient map of the electrode inside the CEBAF inverted gun. The maximum field gradient within the cathode/anode gap is $4.5 \mathrm{MV} / \mathrm{m}$. The gradient at the joint between the insulator and electrode is higher, $\sim 7 \mathrm{MV} / \mathrm{m}$, but does not appear to be problematic. The photograph shows the actual electrode attached to the insulator and $10^{\prime \prime} \mathrm{CF}$ flange, with photocathode puck being installed from behind. 
standard cutting tools and sulfur-free, water-soluble lubricant. Following machining, the parts were degreased in an ultrasonic bath of Micro-90 cleaning solution from ColeParmer, followed by rinses in deionized water, acetone, methanol, and finally boiling deionized water. The electrodes were hand polished [11] with silicon carbide sandpaper using successively finer grit, starting with 300 grit paper and working to 800 grit paper (where the grit designation describes particles per square inch). Care was taken to avoid pressing too hard against the electrode surface to avoid "rolling over" material and trapping abrasive particulate matter under the surface. Electrode parts were further polished with diamond paste, starting with $6 \mu \mathrm{m}$, then $3 \mu \mathrm{m}$, and finally $1 \mu \mathrm{m}$ diamond particles. Parts were degreased after each polishing interval (silicon carbide paper and diamond paste). Finally, parts were high pressure rinsed using a narrow stream of clean deionized water from an oscillating nozzle at $1200 \mathrm{psi}$ for two hours. High pressure rinsing is a standard cleaning technique for niobium superconducting radiofrequency (SRF) cavities [10].

Redesigning the CEBAF photogun to accommodate an inverted high voltage insulator provided an opportunity to improve the vacuum inside the gun high voltage chamber. Three broad goals were pursued: reduce the outgassing rate of the vacuum chamber, reduce the surface area of the vacuum chamber, and increase the amount of pumping.

The vacuum chamber vessel was manufactured from 316L stainless steel, with the L designation indicating "low carbon content." The flanges were made from 316LN stainless steel, with the $\mathrm{N}$ designation indicating "nitrogen enhanced" for hardened knife edges, anticipating hotter bakeout. Thin-walled material was used as much as possible, noting the results of Ref. [21] that indicated much of the gas load of the vacuum chamber originates from thick end flanges. With this in mind, the 13.25" flanges of the previous gun design were eliminated in favor of a dish-head back face with $4.5^{\prime \prime} \mathrm{CF}$ flange, and a flat wall at the front face with a $10^{\prime \prime} \mathrm{CF}$ flange to accommodate the anode structure and provide an opening large enough to install the ten NEG pumps (WP-1250-ST707) that line the bottom of the chamber. The NEG pumps provide an estimated pump speed of $5600 \mathrm{~L} / \mathrm{s}$ (as specified by SAES Getters for full activation) compared to $2300 \mathrm{~L} / \mathrm{s}$ pump speed from the old design with six WP-950-ST707 NEG modules. The NEG pump modules were oriented differently compared to the previous photogun - the accordionshaped NEG modules were rotated 90 degrees to help block "line-of-sight" from the vacuum chamber wall to the photocathode. Ultimately, the cumulative surface area of the new gun, including internal components, was comparable to the old gun design: $\sim 11000 \mathrm{~cm}^{2}$.

Care was taken to follow best-vacuum practices throughout the construction of the photogun vacuum vessel. Parts were manufactured using sulfur-free, water-

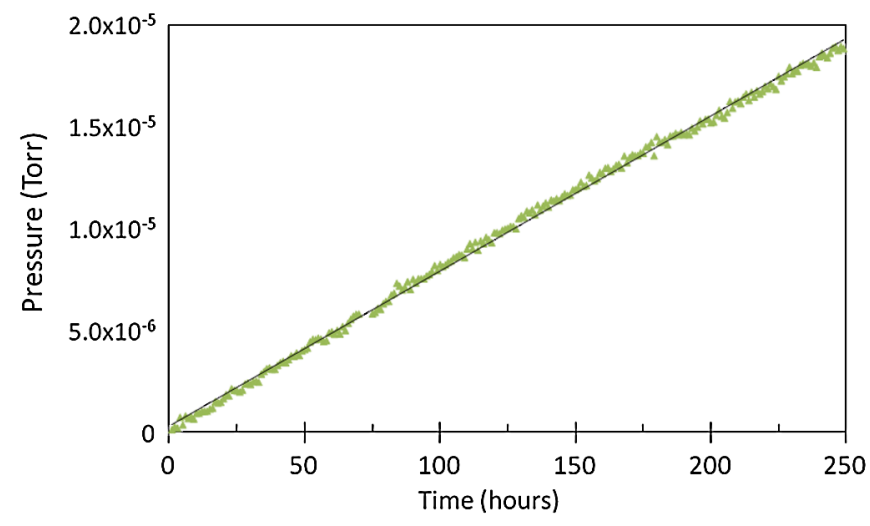

FIG. 3. (Color) Rate-of-rise plot showing pressure inside the unpumped gun high voltage chamber as a function of time, following the $400^{\circ} \mathrm{C}$ vacuum bakeout. Pressure was measured with a spinning rotor gauge. The outgassing rate of the vacuum vessel can be calculated from the slope of the line using Eq. (1).

soluble lubricants and the vendor [22] strived to provide a smooth surface finish. Side ports for an electrical feedthrough, vacuum gauges, and an ion pump were welded to the chamber body without flanges. The chamber was then electropolished and baked at $900^{\circ} \mathrm{C}$ in a vacuum furnace for three hours to reduce outgassing. Finally, flanges were welded to the chamber which was then degreased as described above, and high pressure rinsed per SRF protocol.

Before adding the NEG and ion pumps, the empty chamber was baked at $400^{\circ} \mathrm{C}$ under $\sim 1 \times 10^{-6}$ Torr vacuum for approximately 200 hours, following a similar prescription as Ref. [21]. Afterwards the outgassing rate of the chamber was measured using the "accumulation" technique, by monitoring the rising pressure inside the unpumped chamber with a spinning rotor gauge [23]. The outgassing rate, $Q$, is calculated using

$$
Q\left(\frac{\text { Torr } \cdot L}{s \cdot \mathrm{cm}^{2}}\right)=\frac{\Delta P}{\Delta T} \times \frac{V}{A}
$$

where $\Delta P$ is the pressure change in Torr, $\Delta T$ is the time in seconds, $V$ is the volume in liters, and $A$ is the surface area in $\mathrm{cm}^{2}$. A fit to the data shown in Fig. 3 indicates an outgassing rate of $1 \times 10^{-13} \mathrm{Torr} \mathrm{L} / \mathrm{s} \mathrm{cm}^{2}$, a result that represents an order of magnitude improvement over past CEBAF results obtained with typical $30 \mathrm{~h}$ bakeouts at $250^{\circ} \mathrm{C}[24]$.

\section{INVERTED-GUN PERFORMANCE}

The inverted gun was installed at CEBAF during a scheduled multiweek shutdown. It was baked at $250^{\circ} \mathrm{C}$ for 30 hours and afterwards exhibited good vacuum: $2.9 \times$ $10^{-12}$ Torr as measured with a Leybold extractor gauge (raw value, $N_{2}$ equivalent). The gun was high voltage conditioned to $110 \mathrm{kV}$ without measurable field emission at the isolated anode (zero to within $20 \mathrm{pA}$ ). Beam delivery for nuclear physics experiments commenced quickly and 


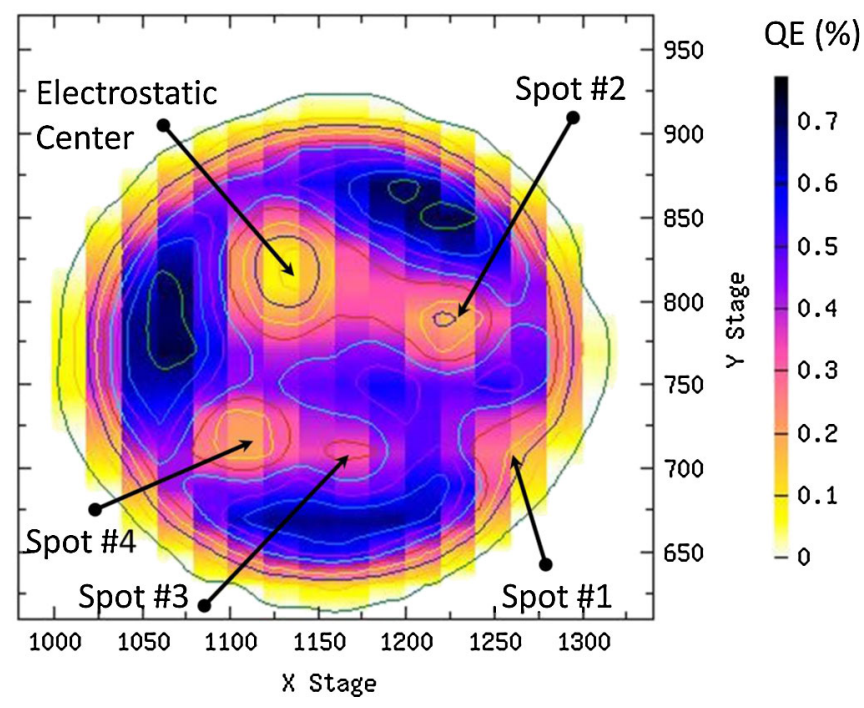

FIG. 4. (Color) A false-color quantum efficiency (QE) map of the strained-superlattice GaAs photocathode inside the CEBAF inverted gun after production beam delivery from four locations (labeled). The map was obtained by scanning the drive laser beam ( $\sim 0.5 \mathrm{~mm}$ FWHM) across the active area of the photocathode (diameter $5 \mathrm{~mm}$ ), and measuring photocurrent at low bias voltage. $X$ and $Y$ units are arbitrary stepper motor intervals.

the gun has been providing highly polarized electron beams ( $\sim 85 \%$ polarization) for months at nominal gun current $\sim 150 \mu \mathrm{A}$. Figure 4 shows a QE map of the photocathode surface after extracting beam for many weeks from four different photocathode locations. The QE map was obtained by scanning a drive laser beam $(\sim 0.5 \mathrm{~mm}$ FWHM) across the active area of the photocathode (diameter $5 \mathrm{~mm}$ ), and measuring photocathode current with $\sim-200 \mathrm{~V}$ bias. Initial QE from a strained-superlattice GaAs/GaAsP photocathode [25] is high $(\sim 1 \%)$ and degrades primarily only at the location of the drive laser beam and along a trench toward the photocathode electrostatic center (as noted in Fig. 4) This QE-decay signature is typical of ion backbombardment [26]. If field emission were present, the QE would decay across the entire photocathode surface.

Photocathode QE is measured daily during production running using each of the three drive laser beams (one laser for each experiment hall). An exponential fit to QE data indicates charge lifetime $\sim 70 \mathrm{C}$ at $150 \mu \mathrm{A}$ (Fig. 5). This represents an improvement over charge lifetime of the previous gun design: $30 \mathrm{C}$ at $60 \mu \mathrm{A}$. Ideally, we would have measured charge lifetime for each gun at the same current, to make an exact comparison of gun performance, but the operating current for each gun was set by the CEBAF experiment requirements.

Of course, it would have been better to observe charge lifetime considerably higher than $70 \mathrm{C}$ from the new inverted gun. It is possible the new gun suffers field emission too but we do not measure it at the isolated anode, or with the sensitive ion pump current monitor. It is also

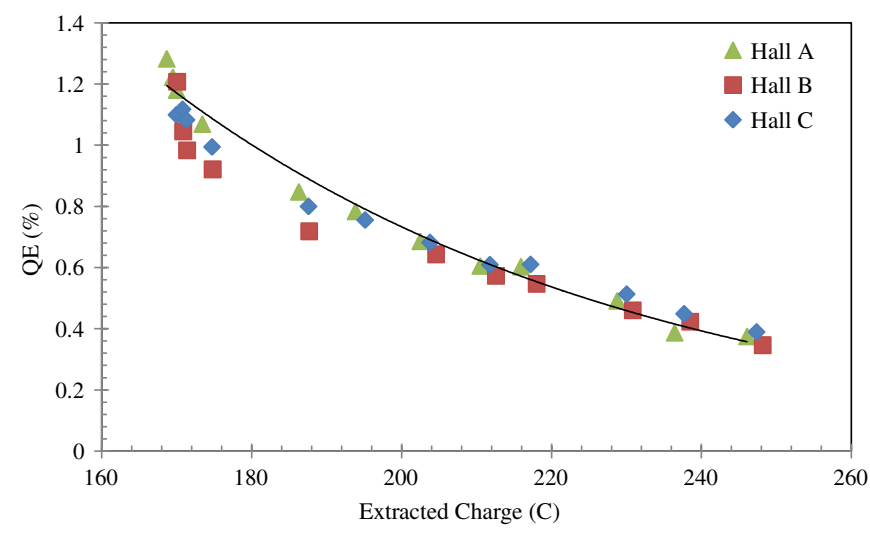

FIG. 5. (Color) A representative plot of daily QE measurements for each drive laser (one per experiment hall) vs extracted charge from the new inverted gun. The data represent QE measurements from one photocathode location, after having already extracted $\sim 170 \mathrm{C}$ from previous locations (i.e., this explains the suppressed zero of the $\mathrm{x}$ axis). A simple exponential fit to the data indicates $1 / e$ charge lifetime of $\sim 70 \mathrm{C}$.

possible the beam line vacuum at the CEBAF photoinjector is not as good as the beam line used at the off-site test stand, where large charge lifetimes were observed. Understanding the factors that limit the charge lifetime of today's inverted gun is the subject of ongoing study.

Another metric-operating lifetime-describes how long the photogun can provide desired beam current before exhausting available QE and laser power. As mentioned above, initial photocathode QE is $\sim 1 \%$ and the fiber-based drive lasers [27] provide roughly $300 \mathrm{~mW}$ maximum power at the photocathode. At $150 \mu \mathrm{A}$ gun current and approximately $10 \mathrm{C}$ of extracted charge per day, the inverted gun can operate for about two weeks before the laser beams must be moved to an unused photocathode location. The $5 \mathrm{~mm}$ diameter photocathode can sustain operation from at least six locations, and thus approximately three months of high average current, highly polarized beam can be delivered before heating and reactivation of the photocathode is required.

\section{CONCLUSION}

We have constructed a new $100 \mathrm{kV}$ dc high voltage GaAs photogun using a compact tapered insulator with inverted geometry. The high voltage design is relatively simple and provides a straightforward means to increase the distance between biased and grounded parts of the photogun, and thereby reduce the field gradient at locations not related to beam transport. The design also significantly reduces the amount of metal biased at high voltage, so there is less metal to polish and less metal to generate field emission. The design has been demonstrated to function reliably at CEBAF.

The inverted insulator approach might be useful for higher voltage photogun projects $(\gg 100 \mathrm{kV}$ ), for ex- 
ample, energy recovered linacs and light sources where emittance requirements are demanding and higher gun voltage serves to improve beam quality. Tests with the same inverted insulator on a dedicated apparatus used to measure field emission from test electrodes [20] indicate it can support operation to at least $225 \mathrm{kV}$, the maximum of our high voltage power supply. This design could prove to be more robust when field emission arises, with electrostatic field lines that help deliver field emitted electrons to the grounded vacuum vessel, rather than the interior surface of a large-bore ceramic insulator, where accumulated electrons can cause catastrophic high voltage breakdown and vacuum failure. With this in mind, a second inverted gun is being constructed at Jefferson Lab for studies at higher voltage, and with a different cathode/anode shape appropriate for beam conditions of the International Linear Collider.

\section{ACKNOWLEDGMENTS}

We thank Fay Hannon of the Jefferson Lab Free Electron Laser Group for providing an electrostatic field gradient map and undergraduate student Melissa Ricketts (University of California, Merced) for making the outgassing measurement of the new gun high voltage chamber. We also thank SCT Ceramics for their enthusiastic support of this project.

[1] C. K. Sinclair, P. A. Adderley, B. M. Dunham, J.C. Hansknecht, P. Hartmann, M. Poelker, J. S. Price, P. M. Rutt, W. J. Schneider, and M. Steigerwald, Phys. Rev. ST Accel. Beams 10, 023501 (2007).

[2] M. Breidenbach, M. Foss, J. Hodgson, A. Kulikov, A. Odian, G. Putallaz, H. Rogers, R. Schindler, K. Skarpaas, and M. Zolotorev, Nucl. Instrum. Methods Phys. Res., Sect. A 350, 1 (1994).

[3] R. Alley, H. Aoyagi, J. Clendenin, J. Frisch, C. Garden, E. Hoyt, R. Kirby, L. Klaisner, A. Kulikov, R. Miller, G. Mulhollan, C. Prescott, P. Saez, D. Schultz, H. Tang, J. Turner, K. Witte, M. Woods, A. D. Yeremian, and M. Zolotorev, Nucl. Instrum. Methods Phys. Res., Sect. A 365, 1 (1995).

[4] K. Aulenbacher, Ch. Nachtigall, H. G. Andresen, J. Bermuth, Th. Dombo, P. Drescher, H. Euteneuer, H. Fischer, D. v. Harrach, P. Hartmann, J. Hoffmann, P. Jennewein, K. H. Kaiser, S. Kobis, H. J. Kreidel, J. Langbein, M. Petri, S. Plutzer, E. Reichert, M. Schemies, H.-J. Schope, K.-H. Steffens, M. Steigerwald, H. Trautner, and Th. Weis, Nucl. Instrum. Methods Phys. Res., Sect. A 391, 498 (1997).

[5] C. W. de Jager, V. Ya. Korchagin, B. L. Militsyn, V. N. Osipov, N. H. Papadakis, S. G. Popov, M. J. J. van den Putte, Yu. M. Shatunov, and Yu. F. Tokarev, The Seventh International Workshop on Polarized Gas Targets and Polarized Beams, AIP Conf. Proc. No. 421 (AIP, New York, 1998), p. 483
[6] E. Tsentalovich, D. Barkhuff, J. Chen, G. Dodson, M. Farkhondeh, W. Franklin, E. Ihloff, F. Kaertner, C. Tschalaer, B. Yang, and T. Zwart, Nucl. Instrum. Methods Phys. Res., Sect. A 582, 413 (2007).

[7] M. Yamamoto, T. Konomi, S. Okumi, Y. Nakagawa, N. Yamamoto, M. Tanioku, X. Jin, T. Ujihara, Y. Takeda, F. Furuta, H. Matsumoto, M. Yoshioka, M. Kuriki, C. Shonaka, and T. Nakanishi, in Proceedings of the 18th International Symposium on High Energy Spin Physics (SPIN2008), AIP Conf. Proc. No. 1149 (AIP, New York, 2008), p. 987.

[8] J. M. Grames, P. A. Adderley, J. Brittian, J. Clark, J. Hansknecht, D. Machie, M. Poelker, M. L. Stutzman, R. Suleiman, and K. Surles-Law, in Proceedings of the 2007 Particle Accelerator Conference, Albuquerque, New Mexico, 2007 (IEEE, Albuquerque, New Mexico, 2007).

[9] J. Hansknecht et al., Proceedings of the 18th International Symposium on High Energy Spin Physics (SPIN2008) (Ref. [7]), p. 1143.

[10] P. Kneisel, in Proceedings of the 32nd Advanced ICFA Beam Dynamics Workshop on Energy Recovering Linacs, edited by S. Chattopadhay and L. Merminga [Nucl. Instrum. Methods Phys. Res., Sect. A 557 (2006)].

[11] J. Francis, SLC Procedural Note FP-238-042-94 (1991) and modifications described in University of Illinois, Nuclear Physics Laboratory Tech Notes: "Notes on Diamond Paste Polishing of Stainless Steel", B. Dunham, 5/19/90—revised 7/23/92, and "Silicon Carbide Grinding of Stainless Steel", D. Engwall, available at http://www.jlab.org/accel/inj_group/docs/NPLTN/list.html.

[12] C. Hernandez-Garcia, S. V. Benson, G. Biallas, D. Bullard, P. Evtushenko, K. Jordan, M. Klopf, D. Sexton, C. Tennant, R. Walker, and G. Williams, Proceedings of the 18th International Symposium on High Energy Spin Physics (SPIN2008) (Ref. [7]), p. 1071.

[13] L. B. Jones, S. P. Jamison, Y. M. Saveliev, K. J. Middleman, and S.L. Smith, Proceedings of the 18th International Symposium on High Energy Spin Physics (SPIN2008) (Ref. [7]), p. 1084.

[14] K. Smolenski, Proceedings of the 18th International Symposium on High Energy Spin Physics (SPIN2008) (Ref. [7]), p. 1077.

[15] SCT Ceramics: http://www.sct-ceramics.com.

[16] There exists a wide variety of industry-standard high voltage connectors to choose from. We chose an insulator that could accept the "R-28" connector used on the Spellman $225 \mathrm{kV}$ high voltage power supply, model XRV225.

[17] Novagard G661 Silicone compound: http://www. eis-inc.com/.

[18] Cathode electrode manufactured from vacuum-arc remelt 316LN stainless steel: tensile strength 71760 psi (slightly lower than requested $75000 \mathrm{psi}$ ), hardness $80 \mathrm{HRB}$, and grain size 4.

[19] Field gradient maps were obtained using commercial software from Computer Simulation Technology (shown): http://www.cst.com/ and Field Precision: http:// www.fieldp.com/.

[20] N. Nishimori et al., ERL09 is an ICFA sponsored workshop, proceedings to be published through JACoW, the 
Joint Accelerator Conferences Website.

[21] C. D. Park, S. M. Chung, Xianghong Liu, and Yulin Li, J. Vac. Sci. Technol. A 26, 1166 (2008).

[22] Vacuum chambers were purchased from Nor-Cal Products and MDC Vacuum Products Corporation.

[23] Spinning Rotor Gauge by MKS Instruments, model SRG2. Measurement technique described by P. A. Redhead, J. Vac. Sci. Technol. A 20, 1667 (2002).

[24] M. L. Stutzman, P. Adderley, J. Brittian, J. Clark, J. Grames, J. Hansknecht, G. R. Myneni, and M. Poelker, Nucl. Instrum. Methods Phys. Res., Sect. A 574, 213 (2007).
[25] SVT associates, Inc., 7620 Executive Drive, Eden Prairie, MN 55344, http://www.svta.com and described in publications: T. Maruyama et al., Appl. Phys. Lett. 85, 2640 (2004); J. E. Clendenin, Proceedings to the 10th Workshop on Polarized Sources and Targets, Novosibirsk, Russia, 2003 [Nucl. Instrum. Methods Phys. Res., Sect. A 536, 308 (2005)].

[26] K. Aulenbacher et al., SLAC Report No. 432, 1993.

[27] J. Hansknecht and M. Poelker, Phys. Rev. ST Accel. Beams 9, 063501 (2006). 